\title{
Article
}

\section{Validity of two clinical knee strength assessments compared to the reference standard}

Weng, P, Janssen, Jessica, Selfe, James and Richards, Jim

Available at http://clok.uclan.ac.uk/12602/

Weng, P, Janssen, Jessica ORCID: 0000-0002-5961-2736, Selfe, James and Richards, Jim ORCID: 0000-0002-4004-3115 (2015) Validity of two clinical knee strength assessments compared to the reference standard. International Journal of Physiotherapy and Research, 3 (6). pp. 1264-1270. ISSN 2321-8975

It is advisable to refer to the publisher's version if you intend to cite from the work. 10.16965/jpr.2015.185

For more information about UCLan's research in this area go to http://www.uclan.ac.uk/researchgroups/ and search for <name of research Group>.

For information about Research generally at UCLan please go to http://www.uclan.ac.uk/research/

All outputs in CLoK are protected by Intellectual Property Rights law, including Copyright law. Copyright, IPR and Moral Rights for the works on this site are retained by the individual authors and/or other copyright owners. Terms and conditions for use of this material are defined in the policies page.

\section{CLoK}

Central Lancashire online Knowledge www.clok.uclan.ac.uk

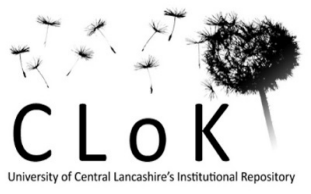




\section{VALIDITY OF TWO CLINICAL KNEE STRENGTH ASSESSMENTS COM PARED TO THE REFERENCE STANDARD}

\section{Philipp Weng ${ }^{* 1}$, Jessie Janssen ${ }^{2}$, Jim D. Richards ${ }^{3}$, James Selfe 4.}

${ }^{* 1}$ Research Intern, Allied Health Research Unit, University of Central Lancashire.

2 Research Fellow, Allied Health Research Unit, School of Sport, Tourism, and the Outdoors, University of Central Lancashire.

${ }^{3}$ Professor of Biomechanics, Allied Health Research Unit, University of Central Lancashire.

${ }^{4}$ Professor of Physiotherapy, Allied Health Research Unit, University of Central Lancashire.

\section{ABSTRACT}

Objectives: Patello femoral Pain (PFP) is the most common lower limb condition encountered in clinical practice. It recently emerged as the third highest ranked topic out of 185 in the Chartered Society of Physiotherapy M usculoskeletal Research Priority Project. For a valid assessment of knee strength during rehabilitation, the isometric test using the isokinetic dynamometer (Cybex) and the hand-held dynamometer (HHD) is not well received with clinical practice. An alternative way is through functional hop tests which clinicians have used to assess their patients' lower extremity muscular strength. This study investigates the validity of knee strength assessments conducted with the HHD and the hoptest compared to the isokinetic dynamometer and also explores differences between genders of the three assessments.

Design: Each assessment included one submaximal and three recorded maximal efforts of the dominant leg. Quadriceps muscle strength was displayed in normalized torques. Correlation coefficients and box-and-whisker plots was used to analyze the data.

Setting: Movement analysis laboratory

Participants: Sixteen males (age $23.5 \pm 4.23$ years, height $1.79 \pm 0.08 \mathrm{~m}$ and body mass $76.21 \pm 10.58 \mathrm{~kg}, \mathrm{BM}$ $23.82 \pm 2.38 \mathrm{~kg} / \mathrm{m}^{2}$ ) and 16 females (age $25.38 \pm 5.49$ years, height $1.67 \pm 0.08 \mathrm{~m}$ and body mass $71.99 \pm 16.05$ $\mathrm{kg}$, BMI $25.83 \pm 4.74 \mathrm{~kg} / \mathrm{m}^{2}$ ) between 18 and 40 years old without any musculoskeletal injuries participated.

Main outcome measures: Knee moments normalized for bodyweight $(\mathrm{Nm} / \mathrm{kg})$ for dynamometers and distance jumped for single legged hoptest.

Results: The strongest significant correlation was found for the comparison between the HHD and Cybex ( $r=0.71$, $\left.r^{2}=0.504, p=0.001\right)$. Correlation between the HHD and hoptest $\left(r=0.4, r^{2}=0.19, p=0.013\right)$, and Cybex and hoptest $\left(r=0.53, r^{2}=0.295, p=0.001\right)$ were poor. Comparing genders, the normalized knee extension moment on the Cybex was $28.8 \%$ lower and with the HHD $22.3 \%$ lower for females.

Conclusions: Single legged hop test appears not to provide a suitable alternative for strength measurement in a clinical setting. Differences in hop performances, especially the use of the arms, seem to be important. Gender differences exist in knee strength assessments. The use of EMG-Analysis in further research might identify differences in muscle recruiting during all three tests.

KEY WORDS: Patello Femoral Pain (PFP), Knee Strength, Assessments, Isokinetic Dynamometer.

Address for correspondence: Philipp Weng, Research Intern, Allied Health Research Unit, University of Central Lancashire. E-Mail: phweng@mail.hs-ulm.de

\section{Access this Article online}

Quick Response code

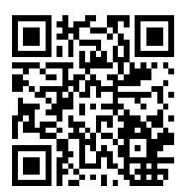

DOI: $10.16965 /$ ijpr.2015.185
International Journal of Physiotherapy and Research

ISSN 2321- 1822

www.ijmhr.org/ ijpr.html

Received: 16-09-2015 Accepted: 01-10-2015

Peer Review: 16-09-2015 Published (0): 11-12-2015

Revised: None
Published (P): 11-12-2015 


\section{INTRODUCTION}

Patellofemoral Pain (PFP), which is prevalent in younger and physically active individuals, is the most common lower limb condition encountered in clinical practice [1]. In PFP significant pain and dysfunction may lead to limitations in societal participation and physical activity [2]. It recently emerged as the third highest ranked topic out of 185 in the Chartered Society of Physiotherapy M usculoskeletal Research Priority Project [3]. Surgical management of PFP is rarely indicated, therefore it is a condition frequently referred for physiotherapy.

Recently an Arthritis Research UK funded a feasibility study to explore subgroups within the patellofemoral population [2]. In this study gender differences were found and "knee strength" was an important factor in defining the subgroups. These data confirm previous observations on the importance of gender in PFP by Boling et al [4] and may shed further light on the gender differences identified in running mechanics [5]. Therefore being able to conduct a valid and yet clinically relevant assessment of lower limb muscle strength is important for PFP.

The gold standard for assessing muscle strength in research is the isokinetic dynamometer which is often used to perform an isometric strength test [6]. Isometric testing is a valuable tool to specifically assess performance of the quadriceps femoris muscles. Because of a lack of available equipment, this test is often not suitable for routine clinical practice [7]. Another commonly used tool in clinical practice is the manual muscle strength measurement, such as the modified Oxford scale. This approach is subjective and cannot differentiate between small strength differences in the higher scales and cannot guarantee reliability [8].

Muscle strength assessment can be improved by measuring the force of quadriceps femoris with a hand-held dynamometer (HHD). This instrumented isometric strength measurement provides clinicians with an objective assessment of the current patient status during rehabilitation [8]. However, feedback from clinicians during the recent ARUK funded study indicated this measurement was not well received with clinical practice. Clinicians reported the HHD measurement was "little bit more fiddly, more difficult to undertake" (PT1) and "fairly difficult to set up" (PT2). One of them reported that "there is quite a high risk of user error there" (PT1), but another physiotherapist indicated that the correct use is just a "practice issue" (PT2). Also one of them said that they "don't have access to them in the clinical practice" (PT3).

It has recently been reported that an alternative way to assess knee strength is through functional hopping tests. A huge variety of hop test procedures have been described $[6,9,10,11$, 12,13 including vertical jump tests, timed hop and single leg hop tests for distance. Clinicians have used single leg hop tests to assess their patients' lower extremity muscular strength and ability to perform tasks that challenge knee stability [14]. These tests are also commonly used to evaluate progress in knee rehabilitation programs [14] or as an objective tool to evaluate a patient's total leg function [7].

The ability to perform a single-legged hop for distance depends on quadriceps strength because a consequence of strength loss is a reduced ability to both, generate and absorb force during activity. However, this type of test also reflects neuromuscular control, power, joint function, and range of motion, as well as the self-esteem and confidence of the participants [15]. Furthermore functional hop tests simulate the forces encountered during sport-specific activity under controlled conditions. [16] Clark (101) describes them as "currently the best measurement tool for the clinical assessment of lower limb function in the absence of sophisticated laboratory based biomechanical analyses". Halabchi et al [17] state the single leg hop test is an important test to evaluate functional muscle performance in patients with PFP.

Further studies as Pincivero et al. [9], Petsching et al. [18], English et al. [7] and Ericsson et al. [19] only assessed the single leg hop test for distance compared to an isokinetic dynamometer. No previous study describes the relationships between a single legged hop test, hand held dynamometer (HHD) and an isokinetic dynamometer test. The aim of this study is 
therefore to compare two clinical knee strength assessments with the reference standard.We hypothesised that hand held dynamometer (HHD) and an isokinetic dynamometer test are well correlated.

\section{METHODS}

Participants: Sixteen males (age $23.5 \pm 4.23$ years, height $1.79 \pm 0.08 \mathrm{~m}$ and body mass 76.21 $\pm 10.58 \mathrm{~kg}, \mathrm{BMI} 23.82 \pm 2.38 \mathrm{~kg} / \mathrm{m}^{2}$ ) and 16 females (age $25.38 \pm 5.49$ years, height $1.67 \pm$ $0.08 \mathrm{~m}$ and body mass $71.99 \pm 16.05 \mathrm{~kg}, \mathrm{BMI}$ $25.83 \pm 4.74 \mathrm{~kg} / \mathrm{m}^{2}$ ) volunteered to take part.

All participants fulfilled the inclusion criteria; age between 18 and 40 years old, no current neuromusculoskeletal injuries or disorders, no history of surgery to the lower extremities. Participants included University staff, students and volunteers from outside the University. All participants provided written informed consent and ethical approval was obtained from the University of Central Lancashire (PsST/2014/007, Dr Hazel Roddam) in accordance with the principles documented in the Declaration of Helsinki. Participants were allowed to withdraw at any given time without providing a reason.

Data Collection: All participants were asked to attend one testing session. Each session lasted approximately 30 minutes and consisted of 3 tasks which were conducted in a randomised order.

The study employed a test-retest design consisting of three different assessments: 1) isometric test with Cybex NORM dynamometer, 2 ) isometric test with a Lafayette hand held dynamometer (Model 01163) and 3) single legged hop test. More information is provided below. Each test was conducted with the dominant leg. Leg dominance was determined by asking the participants which leg they would use to kick a soccer ball [20]. Participant's age, height, weight $[6,18,28,29]$, distance from lateral epicondyle of the knee to centre of both force pads of the dynamometer were measured and recorded in order to calculate the knee extension moment $[9,25]$. Before the assessments every participant completed a warm up consisting of five squats with two repetitions.

With the Cybex NORM dynamometer one submaximal isometric contraction and
3 maximum isometric knee contractions at $90^{\circ}$ knee flexion (as per protocol Cybex NORM handbook) were completed. For data collection participants were asked to perform a resisted exercise seated on an isokinetic machine chair with the tested lower leg strapped to the chair and hands on the chair handles. The hand held dynamometry test included one sub-maximal isometric contraction and 3 maximum isometric knee extension tests at $90^{\circ} \mathrm{knee}$ flexion [2]. For data collection participants were asked to perform a resisted exercise seated on a bench with the tested lower leg strapped to the chair. In the hoptest assessment participants were asked to perform one practice single legged hop test followed by 3 maximum single legged hop tests. From this task participants were asked to stand on one leg, with their hands behind their back and their toe positioned on a piece of tape. They were then asked to execute one warm-up by hopping horizontally and landing on the supporting leg. Three maximal efforts were then recorded, with the participant hopping as far as possible. Failure to land on the supporting leg resulted in additional hop [20]. In all assessments each repetition was followed by a rest period of 20 seconds and the participants were given 1 minute of rest between each trial to prevent fatigue.

Data Analysis: All statistical analysis carried out in Statistical Package for the Social Sciences (SPSS, IBM Version 22, USA). Descriptive statistics for quadriceps muscle strength were displayed in normalised torques by dividing them by bodyweight $(\mathrm{Nm} / \mathrm{kg})$ [7]. Pearson's correlation coefficients $\left(r^{2} \varangle 0.5\right.$ : poor, $r^{2}>0.5$ : good $)$ and boxand-whisker plots were also used to analyse the data. Three by two mixed ANOVA was used to identify significant difference.

\section{RESULTS}

We recorded the data of 35 participants: Threeof them were excluded from analysis; one person refused to give their bodyweight, one person was a professional sprinter and one person had previous experience- with HHD tests.

orrelation between tasks: The majority of participants (30 of 32) showed a higher knee extension moment on the Cybex than with the 
HHD (Table1). All means show a relatively high standard deviation which is also displayed by the Box-and Whisker (Fig. 1).

Fig. 1: Box-and Whisker.

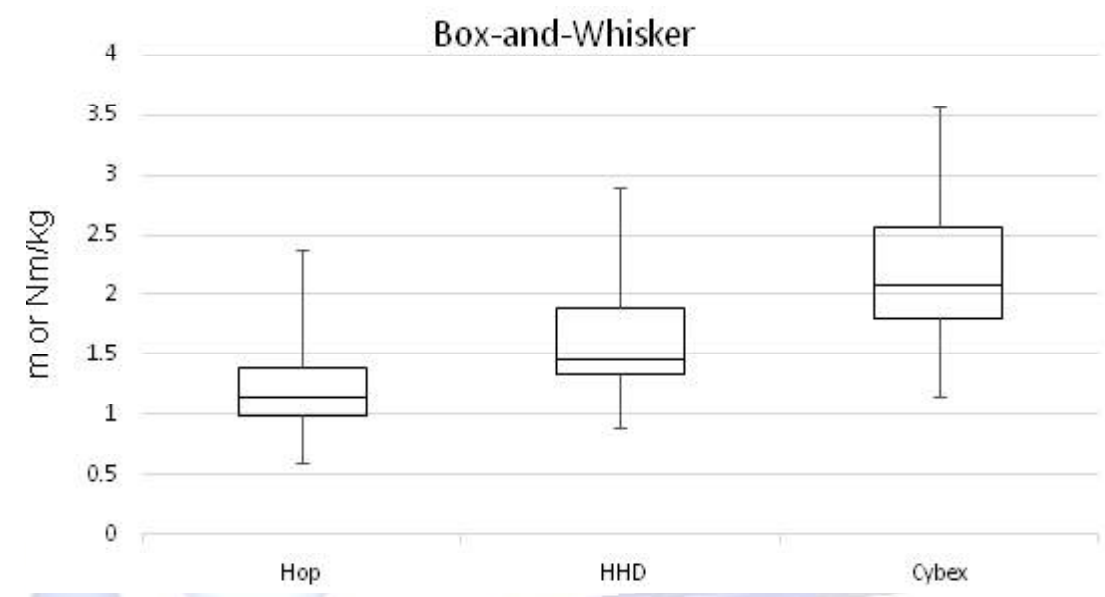

Significant correlations were found for all three comparisons ( $p \varangle 0.05$ ) (Table 2$)$. The relationship between Hop and HHD showed a poor correlation $\left(r=0.436, r^{2}=0.19, p=0.013\right)$, also for Hop and Cybex $\left(r=0.544, r^{2}=0.295, p=0.001\right)$. HHD and Cybex displayed a stronger correlation of $r=0.71\left(r^{2}=\right.$ $0.504, p=0.001$ ). This is supported by the Box-and-Whisker plots (Figure1), which shows the mean values for all participants.

Gender differences: Comparing genders, the normalised knee extension moment scored with the HHD was $22.3 \%$ lower in females than in males (Table 1 ). The corresponding Cybex value was also $28.8 \%$ lower for females.

The correlation between the hop test and the HHD (Table 2 ) was higher value in females $(r=0.427$, $\left.r^{2}=0.182, p=0.099\right)$ than in males $\left(r=285, r^{2}=0.081, p=0.285\right)$. The comparison between the Hop and the Cybex showed a higher correlation in females $\left(r=0.363, r^{2}=0.405, p=0.008\right)$. However, the correlation between HHD and Cybex is lower in females $\left(r=0.515, r^{2}=0.266, p=0.041\right)$ than in males $\left(r=0.702, r^{2}=0.49, p=0.0029\right)$.

Table 1: M ean difference for task and gender. P-values of less than 0.05 indicate a significant difference between genders.

\begin{tabular}{|l|c|c|c|c|}
\hline & all & females & males & \\
\cline { 2 - 5 } & mean (sd) & mean (sd) & mean (sd) & p \\
\hline Hop (m) & $1.19(0.27)$ & $1.08(0.24)$ & $1.30(0.26)$ & 0.019 \\
\hline HHD (Nm/ kg) & $1.58(0.57)$ & $1.37(0.40)$ & $1.80(0.64)$ & 0.032 \\
\hline Cybex (Nm/ kg) & $2.21(0.65)$ & $1.85(0.40)$ & $2.56(0.65)$ & 0.001 \\
\hline
\end{tabular}

Table 2: Correlation between tasks for different genders.

\begin{tabular}{|c|c|c|c|c|c|c|c|c|c|}
\hline & \multicolumn{3}{|c|}{ all } & \multicolumn{3}{c|}{ females } & \multicolumn{3}{|c|}{ males } \\
\hline & $\mathbf{r}$ & $\mathbf{r}^{2}$ & $\mathbf{p}$ & $\mathbf{r}$ & $\mathbf{r}^{2}$ & $\mathbf{p}$ & $\mathbf{r}$ & $\mathbf{r}^{2}$ & $\mathbf{p}$ \\
\hline Hop -HHD & 0.436 & 0.19 & 0.013 & 0.427 & 0.182 & 0.099 & 0.285 & 0.081 & 0.285 \\
\hline Hop -Cybex & 0.544 & 0.295 & 0.001 & 0.363 & 0.405 & 0.008 & 0.294 & 0.086 & 0.269 \\
\hline HHD - Cybex & 0.71 & 0.504 & 0.001 & 0.515 & 0.266 & 0.041 & 0.702 & 0.49 & 0.002 \\
\hline
\end{tabular}

\section{DISCUSSION}

This study investigated the relationships between two different isometric tests and a single legged hop test. The correlation between the HHD and Cybex was good, indicating the HHD can be used in clinical practice. The correlation between the Cybex and hoptest and the HHD and hoptest was poor. This study also added to the existing evidence that gender difference exist when assessing knee strength. 
The single legged hop measuring the distance from heel to toe was used and with hands behind the back. By instructing participants to hold their hands clasped behind the back we excluded the influence of the arms. The aim to achieve the highest concentric performance of the quadriceps femoris muscle, as we felt this would be more highly correlated with the isometric tests. However, the single legged hop test did not show a strong correlation with the isometric tests which is contrary to our previous hypothesis. Therefore this test appears not to provide a suitable alternative for strength measurement in a clinical setting. Wilk et al. [6] $\left(r=0.62 r^{2}=0.38\right)$ and English et al. [7] $(r=0.63$ $r^{2}=0.4$ ) showed a better correlation between the isokinetic test and a single leg hop test with the use of the arms. In contrast, assessments with subjects with anterior cruciate ligament deficiency (Fitzgerald et al. [14], $r=0.06$ $\left.r^{2}=0.0036\right)$ and healthy subjects who were allowed to use their arms (Clark [16], $r=0.37$ $r^{2}=0.137$ ) have been shown to have lower correlations. The upper limbs as a swinging element, could therefore be one of the strongest influencing factors is the knee strength assessments. Interestingly, in a literature review 7 of 18 studies (39\%) [6, 15, 19, 21, 22, 23, 24] relating to the hop test do not describe the use of the arms. Additionally, the method of measuring the distance of the hop differed considerably. Therefore differences in hop performances seem to be important and comparisons between either isometric or isokinetic tests are also important.

In this study the held dynamometer (HHD) and the isokinetic dynamometer (Cybex) showed the highest correlation $\left(r=0.71, r^{2}=0.504\right)$. These findings agree with $\mathrm{M}$ artin et al. [25] and Arnold et al. [26] who concluded, that the use of HHD devices for physiotherapist to assess isometric strength tests in a clinical environment is a valid and cheaper alternative to isokinetic units such as the Cybex in older people. However, it should be noted that two participants reported shin pain during the test where the patient interface of the HHD was placed and the majority of the rest of the participants described this procedure as uncomfortable. This was caused by the small surface area and the high amount of force which resulted in high pressure. In our opinion the design of the patient interface, should be reviewed and possibly modified in order to reduce or avoid discomfort. Any such modifications would need to be undertaken carefully in order to not affect strength measurements. This factor may account for the lower measurements recorded with the HHD as there may have been some pain inhibition preventing stronger contractions.

Our second aim was to explore differences between genders. In previous studies Gustavsson et al [11] and Bremander et al. [12] described significant differences between male and female subjects in the single leg hop for distance, which is supported by our results. A gender difference has also been identified by Russel et al. [27] who showed that women performing a horizontal jump, displayed greater valgus knee angles landing with one leg. These differences in performance and landing biomechanics might have influenced the maximal distance. In addition to the singlelegged hop, tests with the HHD and the isokinetic machine have also shown gender differences. When participants performed a maximal isokinetic and isometric muscle contraction on isokinetic dynamometer (Biodex System 3 PRO), Harbo et al [28] concluded a variation of strength in males. The standard deviation of the residuals of maximal isokinetic knee extension strength was $50 \%$ lower for women than for men, without considering the body weight of the participants. Using an HHD instead of an isokinetic dynanometer, the maximal isometric moment showed a standard error measurement $40 \%$ higherin boys than in girls [29] which supports the previous finding.

The main difference between the HHD and the Cybex test is potentially the back support and the seat angle on the Cybex which might create a feeling of stabilization. The use of EMGAnalysis in further research might identify differences in muscle recruiting during all three tests. With this information the tests could be standardized, but would be less applicationoriented. Future studies could investigate the relationship between isokinetic knee strength and the hop test. M ore information is needed to identify why females show a higher in reliability 
than men comparing the hop, the HHD and the test with the Cybex.

\section{Conflicts of interest: None REFERENCES}

[1]. Powers C, Bolgla L, Callaghan M, Collins N, Sheehan F. Patellofemoral Pain: Proximal, Distal, and Local Factors. J Orthopaedic \& Sports Physical Therapy 2012;42:1-20.

[2]. Selfe J, Callaghan M, Witvrouw E. Targeted intervensions for patellofemoral pain syndrome: classification of clinical subgroups. MBJ Open, 2013;3.

[3]. Rushton A, M oore A. International identification of research priorities for postgraduate theses in musculoskeletal physiotherapy using a modified Delphi technique. Manual Therapy 2010;15:142148.

[4]. Boling M, Padua D, M arshall S, Guskiewicz K, Pyne $\mathrm{S}$, Beutler A. Gender differences in the incidence and prevalence of patellofemoral pain syndrome. Cand J M ed Sci Sports 2010;20:725-730.

[5]. Ferber R, McClay Davis I, Williams DS. Gender differences in lower extremity mechanics during running. Clinic Biomech 2003;18:350-357.

[6]. Wilk KE, Romaniello WT, Soscia SM, Arrigo CA, Andrews JR. The relationship between subjective knee scores, isokinetic testing, and functional testing in the ACL-reconstructed knee. J Orthop Sports Phys Ther. 1994;20:60-73. [PubM ed]

[7]. English R, Brannock M, Ting Chick W, Eastwood L, Uhl T. The Relationship Between Lower Extremity Isokinetic Work and Single-Leg Functional Hop-Work Test. J Sport Rehabilitation 2006;15:95-104.

[8]. Janssen J, Le-Ngoc L. Intratester Reliability and Validity of Concentric M easurements Using a New Hand-Held Dynamometer. Arch Phys Med Rehab, 2009;90.

[9]. Pincivero D, Lephart S, Karunakara R. Effects of rest interval on isokinetic strength and functional performance after short term high intensity training. Br J Sports Med 1997;31:229-234.

[10]. Hopper D M, Goh SC, Wnetworth LA, Chan D, Chau J, Wootton G J, Strauss G R, Boyle J. Teste-retest reliability of knee rating scales and functional hop tests one year following anterior cruciate ligament reconstruction. Physical Therapy in Sports 2002;3:10-108.

[11]. Gustavsson A, Neeter C, Thomee P, Silbernagel K, Augustsson J, Thomee R, Kralsson J. A test battery for evaluating hop performance in patients with a $A C L$ injury and patients who have undergone $A C L$ reconstruction. Knee Surg Sports Traumatol Arthrose 2005;13:778-788.

[12]. Bremander A, Dahl I, RoosE. Validity and reliability of functional performance tests in meniscectomized patients with or without knee osteoarthritis. Scandinavian J Med Sci Sports 2006;17:120-127.

[13]. Hamilton R, Shultz S, Scmitz R, Perrin D. Triple-Hop Distance as a Valid Predictor of Lower Limp Strength and Power. Journal of Athlethic Training 2008;43(2):144-151.

[14]. Fitzgerald G, Lephart S,Hye Hwang J, Wainner M R. Hop Tests as Predictors of Dynamic Knee Stability. J Orthopaedic \& Sports Physical Therapy 2001;31:588-597.

[15]. Eitzen I, Eitzen T, Holm I, Snyder-M ackler L, Risberg M . Anterior Cruciate Ligament- Deficient Potential Corpers and Noncorpers Reveal Different Isokinetic Quadriceps Strength Profiles in the Early Stage After injury. American J Sports Medicine 2010;38:586.

[16]. Clark N. Functional performance testing following knee ligament injury. Physical Therapy in Sport 2001;2:91-105.

[17]. Halabachi F, Mazaheri R, Seif-Baghi T. Patellofemoral Pain Syndrome and Modifiable Intrinsic Risk Faktors: How to Asses and Adress?. Asian J of Sports Medicine 2013;4(2):83-100.

[18]. Petsching R, Baron R, Albrech M. The Relationship Between Isokinetic Quadriceps Strength Test and Hop Tests for Distance and One-Legged Vertical Jump Test Following Anterior Cruciate Ligament Reconstruction. J Orthopaedic \& Sports Physical Therapy 1998;28:1.

[19]. Ericcson Y B, RoosE M , Dahlberg L. M uscle Strength, Functional Performance, and Self-Reported Outcomes Four Years After Arthroscopic Partial Meniscectomy in Middle-Aged Patients. Arthritis \& Rheumatism (Arthritis Care \& Research) 2006;55:946-952.

[20]. Greenberger HB, Paterno M V. Relationship of Knee Extensor Strength and Hopping Test Performance in the Assessment of Lower Extremity Function. Journal of Orthopaedic \& Sports Physical Therapy 1995;22(5)5:202-206.

[21]. Bolgla LA, Keskula DR. Reliability of Lower Extremity Functional Performance Tests, Journal of Orthopaedic \& Sports Physical Therapy 1997;26:3.

[22]. Carter ND, Jenkinson TR, Wilson D, Jones DW, Torode AS. Joint position sense and rehabilitation in the anterior cruciate ligament deficient knee Brj Sports Med. 1997;31:209-212.

[23]. Neeter C, Gustavsson A, Thomee P, Augustsson J, Thomee R, Karlsson J. Development of a strength test battery for evaluating leg muscle power after anterior cruciate ligament injury and reconstruction. Knee Surg Sports Traumatol Arthrosc 2006;14:571-580.

[24]. Ross M D, Irrgang JJ, Denegar CR, McCloy CM, Unangst ET. The relationship between participation restrictions and selected clinical measures following anterior cruciate ligament reconstruction. Knee Surg, Sports Traumatol, Arthrosc 2002; 10:10-19.

[25]. M artin HJ, Yule V, Syddall HE, Dennison EM, Cooper C, Aihie Sayer A. Is Hand-Held Dynamometry Useful for the Measurement of Quadriceps Strength in Older People? A Comparison with the Gold Standard Biodex Dynamometry. Gerontology 2006;52:154159. 
[26]. Arnold CM, Warkentin KD, Chilibeck PD, Magnus CRA. The reliability and validity of handheld dynamometry for the measurement in lowerextremity muscle strength in older adults. J Strength and Conditioning Research 2010;3:815.

[27]. Russel KA, Palmieri RM, Zinder SM, Ingersoll CD. Sex Differences in Valgus Knee Angle During a Single-Leg Drop Jump. J Athletic Training 2006;41(2):166-171.

[28]. Harbo T, Brincks J, Andersen H. M aximal isokinetic and isometric muscle strength of major muscle groups related to age, body mass, height, and sex in 178 healthy subjects. Eur J Appl Physiol 2012;112:267-275.
[29]. Herbert LJ, Maltais DB, Lepage C, Saulnier J, Crete $M$, Perron M. Isometric M uscle Strength in Youth Assessed by Hand-held Dynamometry: A Feasibility, Reliability, and Validity Study. Pediatric Physical Therapy 2011;5669,110, 2303-0289.

How to cite this article:

Philipp Weng, Jessie Janssen, Jim D. Richards, James Selfe. VALIDITY OF TWO CLINICAL KNEE STRENGTH ASSESSM ENTS COM PARED TO THE REFERENCE STANDARD. Int J Physiother Res 2015;3(6):1264-1270. DOI: 10.16965/ijpr.2015.185 